\title{
Valve thrombosis after transcatheter and surgical aortic valve replacement: Incidence and outcomes
}

Thomas J. Cahill, MB BS, DPhil, Omar K. Khalique, MD, Isaac George, MD, and Susheel Kodali, MD

\begin{abstract}
Associate Editor's Introduction-There is an increasing trend toward the use of tissue valves in the aortic position in younger patients, either as a percutaneous option using the transcatheter approach (ie, transcatheter aortic valve replacement) or as a potential "first-stage" with a bioprosthetic valve and an eventual valve-in-valve transcatheter aortic valve replacement down the road. One argument made is that either of these approaches avoids the need for long-term anticoagulation viz-à-viz mechanical valves. Newer imaging techniques have demonstrated subclinical evidence of leaflet thrombosis in tissue valves that could progress in time and alter the rationale for this approach. In this invited expert opinion, the authors review the current literature as well as providing the readership an algorithm in the diagnostic approach and management of patients with suspected leaflet thrombosis.
\end{abstract}

\section{Abe DeAnda Jr, MD}

Transcatheter aortic valve replacement (TAVR) is now the treatment of choice for many patients with symptomatic severe aortic stenosis and suitable anatomy. ${ }^{1}$ While there is randomized trial data to support TAVR across the spectrum of surgical risk, there are remaining uncertainties that limit widespread adoption of TAVR in younger and lowerrisk groups. ${ }^{2}$ One continued issue of concern is valve thrombosis, which has been linked to valve dysfunction, thromboembolism, and structural valve degeneration (SVD).

Valve leaflet thrombosis is seen on both transcatheter and surgical bioprosthetic valves and occurs along a spectrum of severity (Figure 1). ${ }^{4}$ When subclinical, leaflet thrombosis is an incidental abnormality detected on 4-dimensional cardiac computed tomography angiography (CCTA), visualized as hypoattenuated leaflet thickening (HALT) or reduced leaflet motion (RLM), often with no effect on valve function or gradient. Clinical valve thrombosis, however, can result in severe valve dysfunction presenting

\footnotetext{
From the Structural Heart \& Valve Center, New York-Presbyterian Hospital/Columbia University Irving Medical Center, New York, NY.

Received for publication March 31, 2021; revisions received July 21, 2021; accepted for publication July 30, 2021; available ahead of print Sept 4, 2021.

Address for reprints: Susheel Kodali, MD, Avanessians Structural Heart \& Valve Center, NYP/Columbia University Medical Center, 177 Fort Washington Ave, 5th Floor, Room 5C-501, New York, NY 10032 (E-mail: sk2427@cumc.columbia. edu orSKODALI@COLUMBIA.EDU).

J Thorac Cardiovasc Surg 2022;163:1309-15

$0022-5223 / \$ 36.00$

Copyright (C) 2021 by The American Association for Thoracic Surgery

https://doi.org/10.1016/j.jtcvs.2021.07.052
}

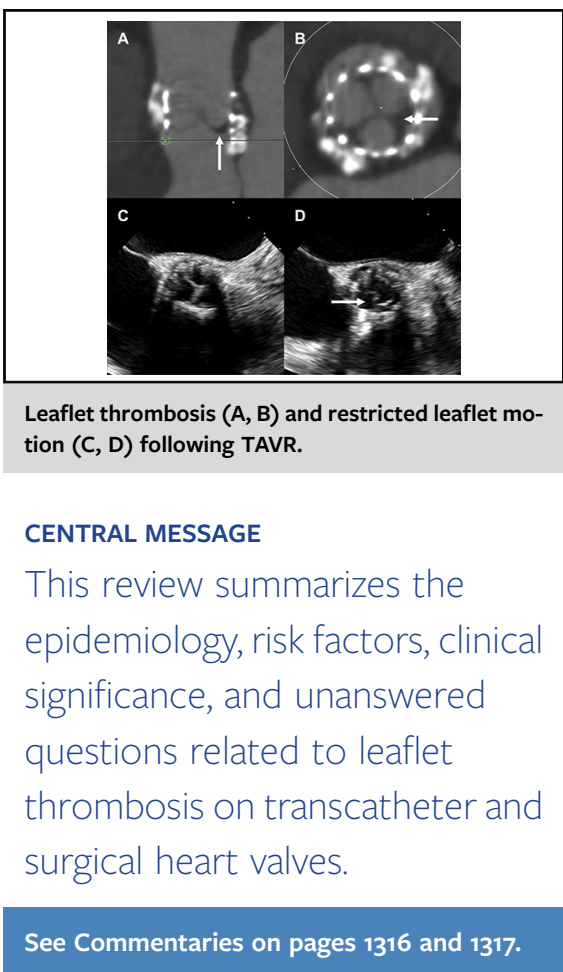

with bioprosthetic valve stenosis, heart failure, or thromboembolism.

Following initial reports of leaflet thrombosis affecting transcatheter heart valves, ${ }^{5,6}$ the US Food and Drug Administration required that the low-risk TAVR trials include a CCTA imaging cohort to further evaluate the significance of HALT and RLM. ${ }^{7}$ Understanding the incidence, risk factors, clinical significance, and treatment of valve leaflet thrombosis has been a focus of intense research over recent years. This review outlines current knowledge regarding subclinical leaflet thrombosis on transcatheter heart valves (THVs) and highlights persistent unanswered questions.

\section{EPIDEMIOLOGY OF LEAFLET THROMBOSIS}

The incidence of valve thrombosis after bioprosthetic surgical aortic valve replacement (SAVR) has been considered to be extremely low, based on historical series of clinical leaflet thrombosis with gross pathologic findings. For example, in a series of 4568 bioprosthetic SAVRs from the Mayo Clinic, only 8 cases of clinical valve thrombosis were identified requiring reoperation within 2 years, an incidence of $0.18 \%{ }^{8}$ More recently, however, in a Mayo Clinic series of 265 patients who required explantation of a 


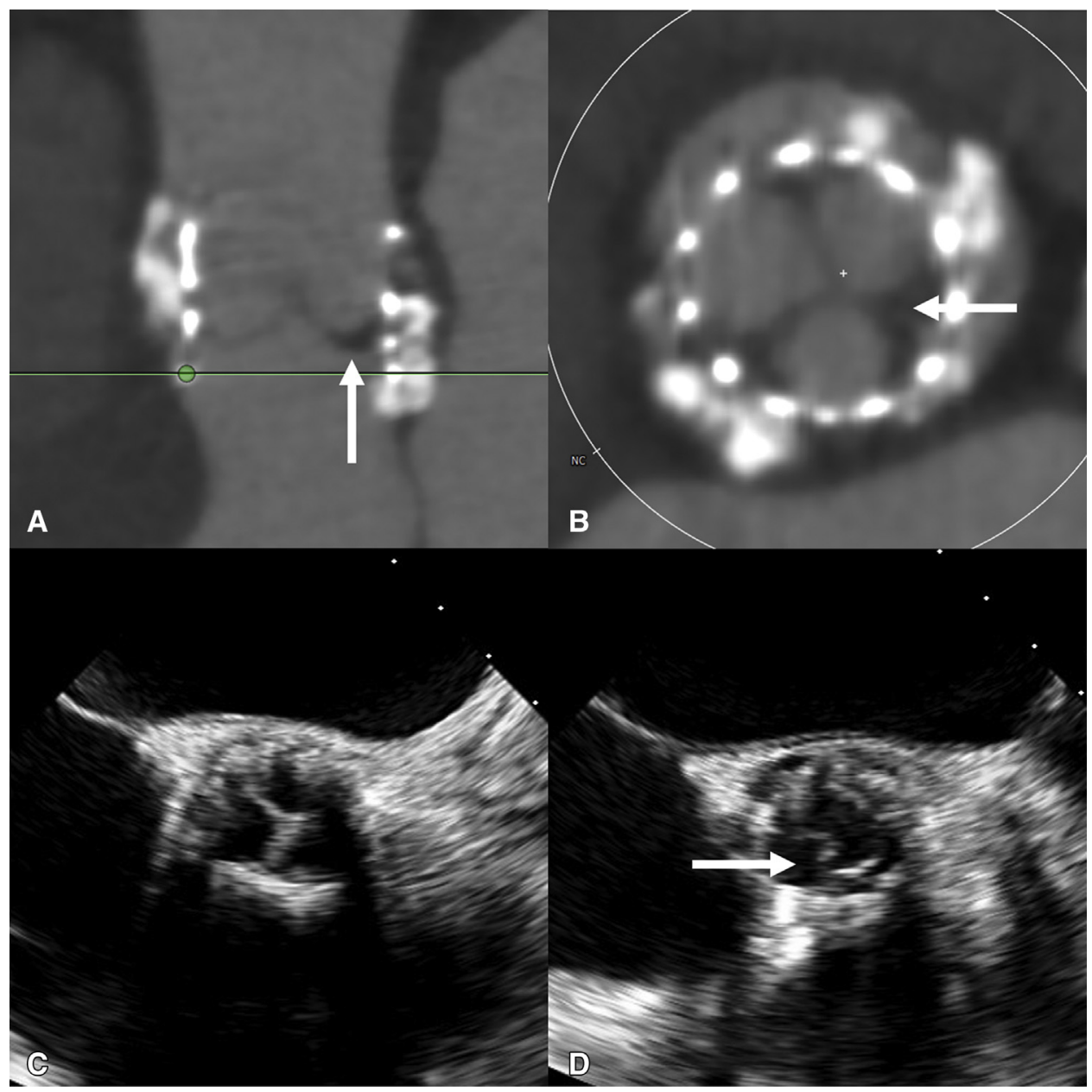

FIGURE 1. A and B, CCTA demonstrating leaflet thrombosis (arrow) in an asymptomatic patient with elevated gradients 5 years after TAVR with 23-mm SAPIEN 3. C and D, Echocardiographic appearances of restricted leaflet motion after TAVR. In systole (D), there is restricted motion of one leaflet (arrow).

surgical aortic bioprosthesis, more than $10 \%$ had macroscopic evidence of thrombosis. ${ }^{9}$ The incidence of subclinical leaflet thrombosis affecting surgical valves has received very minimal focus, however, and until recently, no study had systematically analyzed patients after SAVR for leaflet thrombosis by CCTA. One question that remains is whether some of the early failures of surgical valves are the result of untreated leaflet thrombosis.

Clinical leaflet thrombosis after TAVR is also rare, with an estimated incidence of approximately $0.61 \%-2.8 \%$, based on echo or CCTA imaging (Figure 1). ${ }^{10,11}$ The emergence of widespread CCTA to evaluate THV function after TAVR has led to the recognition of subclinical leaflet thrombosis affecting a significantly greater proportion of both transcatheter and surgical bioprosthetic valves than previously recognized. Systematic CCTA imaging of THVs identified 2 imaging abnormalities consistent with leaflet thrombosis: a semi-lunar region of hypoattenuation at the base of the valve leaflets, termed HALT, and RLM. ${ }^{12}$ The combination of HALT and RLM was labeled hypoattenuation affecting motion.

Following the first report of THV leaflet thrombosis in $2013,{ }^{13}$ several cohorts were subsequently described with an incidence of HALT of $5 \%$ to $40 \%{ }^{5,6,14}$ Leetmaa and colleagues $^{5}$ identified HALT in 5 of $140(4 \%)$ recipients of the SAPIEN XT THV at 1 to 3 months after TAVR. In a prospective analysis of 187 patients across the PORTICO-IDE TAVR trial and 2 registries (RESOLVE [Assessment of Transcatheter and Surgical. Aortic Bioprosthetic Valve Thrombosis and Its Treatment with Anticoagulation] and Subclinical Aortic Valve Bioprosthesis Thrombosis Assessed With 4D CT [SAVORY]), Makkar and colleagues ${ }^{6}$ reported RLM in 22 of $55(40 \%)$ and 17 of $132(13 \%)$ of the trial and registry cohorts, respectively. Patients with RLM were reported to have a greater risk of stroke or transient ischemic attack $(18 \%$ vs $1 \%$, 
$P=.007)$. Hansson and colleagues ${ }^{14}$ analyzed 405 recipients of the SAPIEN XT or $3 \mathrm{THV}$, in which leaflet thrombosis was identified in 28/405 $(7 \%)$ but found no difference in the incidence of stroke in those with HALT at 12-month follow-up.

Multiple cohort studies have since confirmed an incidence of subclinical leaflet thrombosis of approximately $10 \%$ to $15 \%$ following TAVR (Table 1 ). ${ }^{5,6,14-19}$ Sannino and colleagues ${ }^{20}$ have recently reported a meta-analysis addressing the incidence of HALT after TAVR across 22 studies, including a total of 11,567 patients. The overall incidence of subclinical leaflet thrombosis detected at a median of 140 days from TAVR was $15 \%$ (95\% confidence interval [CI], 12\%-20\%). In keeping with HALT representing valve thrombus, the incidence was significantly lower in patients on oral anticoagulation (OAC) compared with antiplatelet therapy $(4 \%$ vs $13 \%$, $P<.0001)$.

Whether there is a difference in the incidence of subclinical leaflet thrombosis after TAVR compared with SAVR has been unclear. This question was addressed directly by the randomized trials of TAVR in patients at low surgical risk. ${ }^{18,19}$ PARTNER 3 (The Placement of Aortic Transcatheter Valve Trial 3) randomized 1000 low-risk patients with severe aortic stenosis to SAVR or TAVR with the balloonexpandable SAPIEN 3 THV. In the computed tomography substudy of 408 patients, 4-dimensional CCTA was performed at 30 days and 1 year. The incidence of subclinical leaflet thrombosis (characterized by HALT with RLM) was $10 \%$ at 30 days after TAVR or SAVR, which increased to $24 \%$ at 1 year. The incidence of HALT at 30 days was significant greater after TAVR compared with SAVR $(13 \%$ vs $5 \%$, RR, 2.64; 95\%, CI 1.11-6.32), but at 1 year this difference was no longer statistically significant ( $28 \%$ vs $20 \%$, RR, 1.38; 95\% CI, 0.87-2.18). Patients with HALT present at 30 days and 1 year had a greater mean aortic valve gradient compared with those without HALT at either time point $(17.8 \pm 2.2 \mathrm{~mm} \mathrm{Hg}$ vs $12.7 \pm 0.3 \mathrm{~mm} \mathrm{Hg}$, $P=.04)$. The Evolut Low-Risk trial, which randomized patients to SAVR or TAVR with the self-expandable Evolut THV, demonstrated very similar rates of THV thrombosis between TAVR and SAVR valves, with a frequency of HALT of $30.9 \%$ for TAVR and $28.4 \%$ for SAVR at 1 year $(P=.661) .{ }^{19}$ There was no relationship between

TABLE 1. Key studies evaluating the incidence of leaflet thrombosis after TAVR and SAVR

\begin{tabular}{|c|c|c|c|c|}
\hline Study & $\mathbf{N}$ & Valve & $\begin{array}{c}\text { Time to CT } \\
\text { median (IQR), d }\end{array}$ & $\begin{array}{c}\text { Incidence of THV } \\
\text { thrombosis }\end{array}$ \\
\hline Leetmaa et al, $2015^{5}$ & 140 & SAPIEN XT & 91 (IQR 66-92) & HALT: $4 \%(5 / 101)$ \\
\hline Makkar et al, $2015^{6}$ & 187 (55 trial, 132 registry) & $\begin{array}{r}\text { Portico, SAPIEN } \\
\text { XT, CoreValve }\end{array}$ & $\begin{array}{l}\text { Trial: } 32 \text { (IQR 28-37) } \\
\text { Registry: } 87 \text { (IQR 7-1851) }\end{array}$ & $\begin{array}{r}\text { RLM: } 55 \%(22 / 55) \text { in trial, } \\
13 \%(17 / 132) \text { in registry }\end{array}$ \\
\hline Hansson et al, $2016^{14}$ & 405 & SAPIEN XT/3 & $1-3 \mathrm{mo}$ & HALT: $7 \%(28 / 405)$ \\
\hline Chakravarty et al, $2017^{15}$ & 890 & $\begin{array}{l}\text { Multiple } \\
\text { (TAVR and SAVR) }\end{array}$ & $\begin{array}{l}\text { Overall cohort: } 83 \\
\quad \text { (IQR 33-281) } \\
\text { SAVR: } 163(79-417) \\
\text { TAVR: } 58(32-236)\end{array}$ & $\begin{array}{l}\text { HAM: whole cohort, } \\
12 \%(106 / 890) \\
\text { TAVR } 13 \%(101 / 752) \\
\text { SAVR } 4 \%(5 / 138) P=.001\end{array}$ \\
\hline Ruile et al, $2018^{16}$ & 754 & Multiple TAVR valves & 5 (IQR 4-6) & $\begin{array}{l}\text { HALT ( } \pm \text { HAM): } 15.9 \% \\
\quad(120 / 754)\end{array}$ \\
\hline Yanagisawa et al, $2019^{17}$ & 485 & SAPIEN XT/3, CoreValve & Median $3 \mathrm{~d}$ & HALT: $9.3 \%(45 / 485)$ \\
\hline $\begin{array}{l}\text { Makkar et al, } 2019^{18} \\
\text { PARTNER } 3 \text { CT Sub-Study }\end{array}$ & 284 (at $30 \mathrm{~d})$ & SAPIEN 3 & $30 \mathrm{~d}$ and $1 \mathrm{y}$ & $\begin{array}{l}\text { HALT } \\
\text { • } 30 \mathrm{~d}: \text { TAVR } 13.3 \%, \\
\text { SAVR 5.0\% }(P=.03) \\
\text { - } 1 \text { y: TAVR } 27.5 \%, \\
\text { SAVR } 20.2(P=.19)\end{array}$ \\
\hline $\begin{array}{l}\text { Blanke et al, } 2020^{19} \\
\text { Evolut Low Risk Sub-Study }\end{array}$ & 375 (at $30 \mathrm{~d}$ ) & $\begin{array}{l}\text { CoreValve, Evolut R, } \\
\text { Evolut PRO }\end{array}$ & $30 \mathrm{~d}$ and $1 \mathrm{y}$ & $\begin{array}{l}\text { HALT } \\
\text { - } 30 \text { d: TAVR } 17.3 \% \text {, } \\
\text { SAVR } 16.5 \% \\
\text { - } 1 \text { y: TAVR } 30.9 \% \text {, } \\
\text { SAVR } 28.4 \% \\
\text { RLM } \\
\text { - } 30 \text { d: TAVR } 14.6 \% \text {, } \\
\text { SAVR } 14.3 \% \\
\text { - } 1 \text { y: TAVR } 31.0 \% \text {, } \\
\text { SAVR } 27.0 \%\end{array}$ \\
\hline
\end{tabular}

$C T$, Computed tomography; $I Q R$, interquartile range; $T H V$, transcatheter heart valve; $H A L T$, hypoattenuated leaflet thickening; TAVR, transcatheter aortic valve replacement; $S A V R$, surgical aortic valve replacement; RLM, reduced leaflet motion; HAM, hypoattenuation affecting motion; PARTNER, Placement of AoRTic TraNscathetER Valve Trial. 
HALT and valve hemodynamic status. These 1-year data suggest that subclinical leaflet thrombosis is dynamic and affects both THV and surgical bioprostheses, without a statistically significant difference in incidence between the 2 groups. However, consistent with previous registries, the incidence is numerically greater in the TAVR group. Medium- and long-term follow-up are ongoing to assess the incidence over time and the significance of leaflet thrombosis as a potential precursor to SVD.

\section{MECHANISMS OF THV THROMBOSIS}

Several patient and valve risk factors for subclinical leaflet thrombosis after TAVR have been reported. ${ }^{11,17}$ Mechanistically, many of these factors appear to act either by modification of flow dynamics around the THV or the local/systemic coagulation cascade, but the precise pathophysiology and timing of thrombus formation remains incompletely understood. Patient factors include obesity, low-flow, and lack of oral anticoagulant therapy. ${ }^{11,17}$ Device and procedural risk factors include balloon-expandable valves, large THV size, valve underexpansion, patientprosthesis mismatch, and valve-in-valve TAVR. ${ }^{11,14,21}$

Understanding the interplay of patient and valve risk factors to predict leaflet thrombosis is the focus of ongoing research. Stasis in the neosinus between the native aortic valve leaflets and the TAVR leaflets may be a key mediator of thrombus formation, and quantification of stasis using patient-specific in vitro modeling has been shown to correlate with thrombus volume. ${ }^{22}$ The mechanism of thrombus formation also differs according to THV design: low implant depth correlates with thrombus volume for the self-expanding CoreValve/Evolut system, suggesting blood stasis in the neosinus is the key mediator. In contrast, thrombus on the SAPIEN 3 system is associated with valve overexpansion. ${ }^{23}$ These local hemodynamic factors are likely to interact with changes in systemic coagulation after TAVR. For example, following valve replacement for severe aortic stenosis, there is rapid recovery of prothrombotic von Willebrand multimers that were previously sheared on the valve. ${ }^{24}$

\section{CLINICAL RELEVANCE}

The relevance of subclinical leaflet thrombosis remains an issue of ongoing debate. An early study of patients in the RESOLVE/SAVORY registries suggested a possible link to thromboembolism, with a greater incidence of transient ischemic attack (but not stroke) detected in patients with subclinical leaflet thrombosis $(5 \%$ vs $1 \%$, $P=.002) .{ }^{15}$ Subsequently, however, no significant association has been demonstrated, with 2 recent meta-analyses confirming that across multiple studies there is no difference in the risk of stroke and transient ischemic attack or all-cause mortality in patients with subclinical leaflet thrombosis compared with those without. ${ }^{20,25}$
The possibility of a link between subclinical leaflet thrombosis and SVD has also been suggested. Greater degrees of HALT are associated with elevated transvalvular gradient and the use of anticoagulant therapy after TAVR has been linked to increased durability. ${ }^{26}{ }^{18} \mathrm{~F}$-fluoride positron emission tomography-computed tomography signal on bioprosthetic valves has been shown to predict SVD, and in some cases, colocalizes with thrombus (as well as pannus and calcification) on explanted valves. ${ }^{27}$ Histopathologic analysis of explanted THVs suggests a possible sequence of progression from thrombosis, followed by fibrosis, and over the long term ( $>4$ years), calcification. ${ }^{28}$ Ascertaining whether leaflet thrombosis is a direct precursor to SVD in a specific patient is challenging, due to the lack of long-term follow-up of individual patients with HALT and RLM. It is clear that the natural history of leaflet thrombosis is dynamic and highly variable, with both progression and spontaneous regression observed. In the SAVORY registry, HALT was initially observed in 32 patients $(38.1 \%)$, with hypoattenuation affecting motion in $17(20.2 \%)$. Between the first CCTA at $140 \pm 152$ days and the second at $298 \pm 141$ days, there was progression in $13(15.5 \%)$ and regression in $9(10.7 \%)$ patients. ${ }^{29}$ In PARTNER 3, spontaneous resolution of HALT (at 30 days) occurred in $54 \%$ of patients at 1 year. ${ }^{18}$ Conversely, new HALT (not identified at 30 days) was observed in $21 \%$ of patients at 1 year.

\section{DIAGNOSIS AND MANAGEMENT}

Investigation of suspected leaflet thrombosis after TAVR is outlined in Figure 2. Routine screening for leaflet thrombosis by CCTA is currently not recommended outside the research setting. If patients develop new exertional symptoms or show elevated transaortic gradients on transthoracic echo, 4-dimensional CCTA assessment for HALT \pm RLM is indicated. Patients presenting with transient ischemic attack, stroke, or systemic embolism following recent TAVR should also undergo transthoracic echocardiography and CCTA to investigate for possible valve thrombosis. If confirmed, oral anticoagulation, including vitamin $\mathrm{K}$ antagonists and direct oral anticoagulants (OACs), are effective for treatment of bioprosthetic valve thrombosis, with resolution of HALT/RLM on CCTA imaging and reduction in transvalvular gradient. ${ }^{30}$ After cessation of OAC, however, there is significant risk of relapse with further leaflet thrombosis. ${ }^{31}$ Oral anticoagulation also appears to prevent formation of leaflet thrombus: in PARTNER 2, oral anticoagulation (predominantly warfarin) was associated with a lower incidence of increase in mean gradient $>10 \mathrm{~mm} \mathrm{Hg}$ in the first year after implantation, likely due to a reduction in leaflet thrombosis. ${ }^{32}$ Ultimately, the duration of oral anticoagulation is an individualized decision based on the patient's estimated risks of recurrent valve thrombosis weighed against the risk of bleeding. 


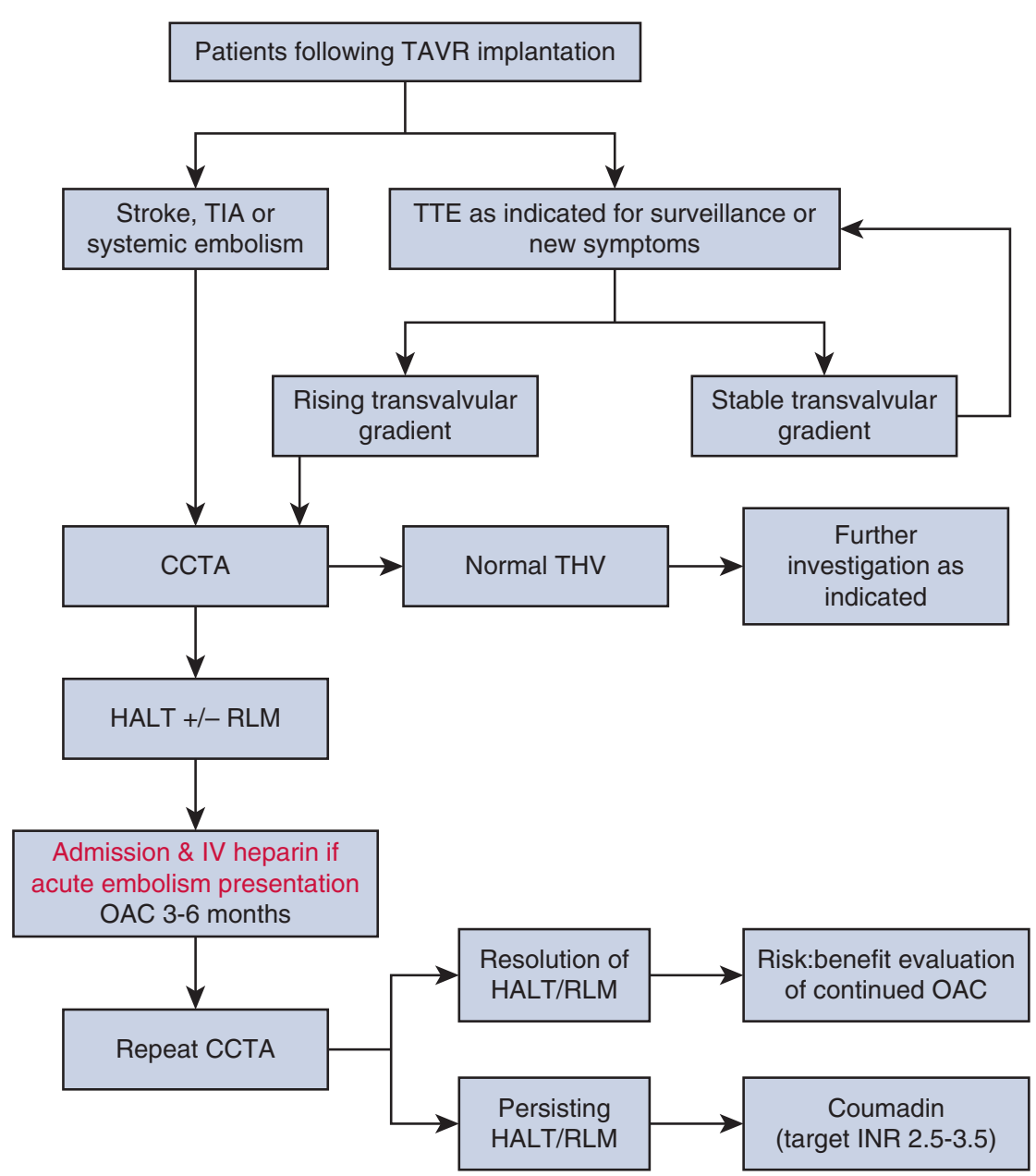

FIGURE 2. Algorithm for diagnosis and management of leaflet thrombosis following TAVR. TAVR, Transcatheter aortic valve replacement; TIA, transient ischemic attack; TTE, transthoracic echocardiography; CCTA, cardiac computed tomography angiography; THV, transcatheter heart valve; HALT, hypoattenuated leaflet thickening; $R L M$, reduced leaflet motion; $O A C$, oral anticoagulation; $I N R$, international normalized ratio.

Although oral anticoagulation has been demonstrated to reduce the incidence of leaflet thrombosis (Table 2), ${ }^{33,34}$ routine use of oral anticoagulation after TAVR appears to lead to excess bleeding which outweighs antithrombotic effects. The GALILEO study evaluated the role of rivaroxaban $10 \mathrm{mg}$ daily (alongside aspirin 75-100 $\mathrm{mg}$ daily for 3 months), compared with aspirin 75 to $100 \mathrm{mg}$ daily (with clopidogrel $75 \mathrm{mg}$ daily for 3 months) in patients undergoing TAVR without an established indication for anticoagulation. ${ }^{35}$ Rivaroxaban was more effective than antiplatelet therapy at prevention of leaflet thickening. Thickening of at least one leaflet was observed in $12.4 \%$ in the rivaroxaban group versus $32.4 \%$ in the antiplatelet group (difference, -20.0 percentage points; $95 \%$ CI, -30.9 to -8.5 ), but the trial was stopped early due to an excess of death or first thromboembolism in the rivaroxaban group and an increase in major, disabling, or lifethreatening bleeding. ${ }^{33}$ It remains unclear whether selective use of oral anticoagulation may be beneficial in specific patient subgroups, however. These include those at elevated risk of leaflet thrombosis with low bleeding risk, such as patients after valve-in-valve TAVR, or in patients with subclinical leaflet thrombosis and elevated transvalvular gradient.

\section{FUTURE QUESTIONS}

There are several key questions that are the focus of ongoing research. First, can the incidence of THV leaflet thrombosis be reduced by optimization of valve selection, sizing, or implantation technique? For example, thrombosis may be reduced by postdilatation to ensure optimal THV expansion, or the use of self-expanding valves. Second, what are the precise pathophysiologic mechanisms of leaflet thrombosis, and can the design of future generations of THVs be iterated to reduce the risk? Possible approaches include modified leaflet composition, drug impregnation of leaflets to reduce thrombogenicity, alternative fixation regimens, or a transition toward tissue-engineered or synthetic 
TABLE 2. Randomized trials evaluating anticoagulation for prevention of leaflet thrombosis after TAVR

\begin{tabular}{|c|c|c|c|c|c|}
\hline Study & Population & Design & Primary end point & Results & Comment \\
\hline GALILEO-4D ${ }^{33}$ & $\begin{array}{l}231 \text { patients without } \\
\text { indication for OAC } \\
\text { undergoing TAVR }\end{array}$ & $\begin{array}{l}\text { RCT: Rivaroxaban } \\
10 \text { mg plus aspirin } \\
75-100 \text { mg daily } \\
\text { compared with } \\
\text { DAPT (clopidogrel } \\
\text { and aspirin) }\end{array}$ & $\begin{array}{l}\text { Percentage of patients } \\
\text { with at least } 1 \\
\text { prosthetic valve } \\
\text { leaflet with grade } 3 \\
\text { or greater motion } \\
\text { reduction }\end{array}$ & $\begin{array}{l}\text { Primary end point } \\
\text { Rivaroxaban }+ \text { aspirin: } 2 / 97 \\
\quad(2.1 \%) \\
\text { DAPT: } 11 / 101(10.9 \%) \\
\text { Difference, }-8.8 \%, 95 \% \mathrm{CI} \text {, } \\
\quad-16.5 \text { to }-1.9, P=.01\end{array}$ & $\begin{array}{l}\text { Reduction in reduced leaflet } \\
\text { motion and leaflet } \\
\text { thickening with } \\
\text { rivaroxaban, but main } \\
\text { GALILEO trial } \\
\text { demonstrated greater risk } \\
\text { of death or thromboembolic } \\
\text { complications (HR, 1.35) } \\
\text { and a greater risk of life- } \\
\text { threatening, disabling or } \\
\text { major bleeding (HR, 1.50) }\end{array}$ \\
\hline Rogers et $\mathrm{al}^{34}$ & $\begin{array}{l}94 \text { patients at low } \\
\text { surgical risk } \\
\text { undergoing } \\
\text { TF-TAVR }\end{array}$ & $\begin{array}{l}\text { Open label, RCT: } \\
\text { aspirin (low dose) } \\
\text { vs aspirin (low } \\
\text { dose) plus warfarin }\end{array}$ & $\begin{array}{l}\text { Composite of HALT } \\
\text { on CCTA, } \\
\text { moderately reduced } \\
\text { leaflet motion, } \\
\text { hemodynamic } \\
\text { aortic valve } \\
\text { dysfunction, stroke/ } \\
\text { TIA at } 30 \mathrm{~d}\end{array}$ & $\begin{array}{l}\text { Primary end point } \\
\text { Aspirin: } 26.5 \% \\
\text { Aspirin plus warfarin: } 7.0 \% \\
P=.013 \\
\text { HALT } \\
\text { Aspirin: } 16.3 \% \\
\text { Aspirin plus warfarin: } 4.7 \% \\
P=.07 \\
\text { RLM } \\
\text { Aspirin } 10.4 \% \\
\text { Aspirin plus warfarin: } 2.3 \% \\
P=.12\end{array}$ & $\begin{array}{l}\text { Reduction in composite } \\
\text { primary end point in the } \\
\text { aspirin plus warfarin arm } \\
\text { Small study with short follow- } \\
\text { up } \\
\text { Low risk population } \\
\text { No excess bleeding at } 30 \mathrm{~d} \\
\text { with anticoagulation }\end{array}$ \\
\hline
\end{tabular}

$O A C$, Oral anticoagulation; $T A V R$, transcatheter aortic valve replacement; $R C T$, randomized controlled trial; $D A P T$, dual antiplatelet therapy; $C I$, confidence interval; $H R$, hazard ratio; $T F$, transfemoral; $H A L T$, hypoattenuated leaflet thickening; $C C T A$, cardiac computed tomography angiography; $T I A$, transient ischemic attack; $R L M$, reduced leaflet motion.

polymer heart valves. ${ }^{36}$ Third, is subclinical leaflet thrombosis mechanistically linked to structural valve degeneration and premature valve failure? If so, should all patients undergo routine CCTA surveillance after TAVR to screen for leaflet thrombosis? If so, at which time points since leaflet thrombosis appears to be a dynamic process? Finally, should patients with subclinical leaflet thrombosis, or at high risk of thrombus formation, receive OAC? While it is clear from the GALILEO trial that OAC is harmful in all-comers after TAVR, it is less clear how to balance the potential risks and benefits of OAC in those with HALT.

\section{CONCLUSIONS}

Randomized TAVR trials have demonstrated promising data in patients at low surgical risk over 2-year follow-up; however, confirmation of long-term function and durability in THVs is a key issue before TAVR can be adopted routinely in younger patients. Subclinical leaflet thrombosis on CCTA, seen as HALT/RLM, affects approximately $10 \%$ to $15 \%$ of patients after both TAVR and SAVR. To date, studies that have directly compared the incidence of subclinical leaflet thrombosis in equivalent patient populations after TAVR and SAVR show no statistically significant difference, although the duration of follow-up remains relatively short and studies are small. Leaflet thrombosis is dynamic, frequently regresses without treatment, and, if required, is effectively treated with OAC. The clinical impact of leaflet thrombosis remains uncertain: while there appears to be no link with stroke or transient ischemic attack, it remains unclear whether leaflet thrombus is associated with fibrosis, calcification, and future SVD. Dedicated studies with long-term follow-up are required to understand the natural history, define patient-specific risk, and determine tailored treatment strategies.

\section{Conflict of Interest Statement}

Dr Khalique is a consultant for Boston Scientific, Edwards Lifesciences, and Abbott Structural. All other authors reported no conflicts of interest.

The Journal policy requires editors and reviewers to disclose conflicts of interest and to decline handling or reviewing manuscripts for which they may have a conflict of interest. The editors and reviewers of this article have no conflicts of interest.

\section{References}

1. Cahill TJ, Chen M, Hayashida K, Latib A, Modine T, Piazza N, et al. Transcatheter aortic valve implantation: current status and future perspectives. Eur Heart J. 2018;39:2625-34.

2. Siontis GCM, Overtchouk P, Cahill TJ, Modine T, Prendergast BP, Praz F, et al. Transcatheter aortic valve implantation vs. surgical aortic valve replacement for treatment of symptomatic severe aortic stenosis: an updated meta-analysis. Eur Heart J. 2019;40:3143-53. 
3. Dvir D, Bourguignon T, Otto Catherine M, Hahn RT, Rosenhek R, Webb JG, et al. Standardized definition of structural valve degeneration for surgical and transcatheter bioprosthetic aortic valves. Circulation. 2018;137:388-99.

4. Ng ACT, Holmes DR, Mack MJ, Delgado V, Makkar R, Blanke P, et al. Leaflet immobility and thrombosis in transcatheter aortic valve replacement. Eur Heart J. 2020;41:3184-97.

5. Leetmaa T, Hansson Nicolaj C, Leipsic J, Jensen K, Poulsen SH, Andersen HR, et al. Early aortic transcatheter heart valve thrombosis. Circ Cardiovasc Interv. 2015;8:e001596.

6. Makkar RR, Fontana G, Jilaihawi H, Chakravarty T, Kofoed KF, De Backer O, et al. Possible subclinical leaflet thrombosis in bioprosthetic aortic valves. $N$ Engl J Med. 2015;373:2015-24.

7. Laschinger JC, Wu C, Ibrahim NG, Shuren JE. Reduced leaflet motion in bioprosthetic aortic valves — the FDA perspective. N Engl J Med. 2015;373:1996-8.

8. Brown ML, Park SJ, Sundt TM, Schaff HV. Early thrombosis risk in patients with biologic valves in the aortic position. J Thorac Cardiovasc Surg. 2012;144: 108-11.

9. Egbe A, Pislaru S, Pellikka P, Poterucha JT, Schaff HV, Maleszewski JJ, et al, Bioprosthetic valve thrombosis versus structural failure. J Am Coll Cardiol. 2015;66:2285-94

10. Latib A, Naganuma T, Abdel-Wahab M, Danenberg H, Cota L, Barbanti M, et al. Treatment and clinical outcomes of transcatheter heart valve thrombosis. Circ Cardiovasc Interv. 2015:8:e01779.

11. Jose J, Sulimov DS, El-Mawardy M, Sato T, Allali A, Holy EW, et al. Clinical bioprosthetic heart valve thrombosis after transcatheter aortic valve replacement: incidence, characteristics, and treatment outcomes. JACC Cardiovasc Interv. 2017; 10:686-97.

12. Jilaihawi H, Asch FM, Manasse E, Ruiz C, Jelnin V, Kashif M, et al. Systematic CT methodology for the evaluation of subclinical leaflet thrombosis. JACC: Cardiovasc Imaging. 2017;10:461-70.

13. Pache G, Blanke P, Zeh W, Jander N. Cusp thrombosis after transcatheter aortic valve replacement detected by computed tomography and echocardiography. Eur Heart J. 2013;34:3546.

14. Hansson NC, Grove EL, Andersen HR, Leipsic J, Mathiassen ON, Jensen JM, et al. Transcatheter aortic valve thrombosis: incidence, predisposing factors, and clinical implications. J Am Coll Cardiol. 2016;68:2059-69.

15. Chakravarty T, Sondergaard L, Friedman J, De Backer O, Berman D, Kofoed KF, et al. Subclinical leaflet thrombosis in surgical and transcatheter bioprosthetic aortic valves: an observational study. Lancet. 2017;389:2383-92.

16. Ruile P, Minners J, Breitbart P, Schoechlin S, Gick M, Pache G, et al. Mediumterm follow-up of early leaflet thrombosis after transcatheter aortic valve replacement. JACC Cardiovasc Interv. 2018;11:1164-71.

17. Yanagisawa R, Tanaka M, Yashima F, Arai T, Jinzaki M, Shimizu H, et al. Early and late leaflet thrombosis after transcatheter aortic valve replacement. Circ Cardiovasc Interv. 2019;12:e07349.

18. Makkar RR, Blanke P, Leipsic J, Thourani V, Chakravarty T, Brown D, et al. Subclinical leaflet thrombosis in transcatheter and surgical bioprosthetic valves: PARTNER 3 cardiac computed tomography substudy. J Am Coll Cardiol. 2020;75:3003-15.

19. Blanke P, Leipsic JA, Popma JJ, Yakubov SJ, Deeb GM, Gada H, et al. Bioprosthetic aortic valve leaflet thickening in the evolut low risk sub-study. J Am Coll Cardiol. 2020;75:2430-42.

20. Sannino A, Hahn RT, Leipsic J, Mack MJ, Grayburn PA. Meta-analysis of incidence, predictors and consequences of clinical and subclinical bioprosthetic leaflet thrombosis after transcatheter aortic valve implantation. Am J Cardiol. 2020;132:106-13.
21. Khodaee F, Barakat M, Abbasi M, Dvir D, Azadani AN. Incomplete expansion of transcatheter aortic valves is associated with propensity for valve thrombosis Interact Cardiovasc Thorac Surg. 2020;30:39-46.

22. Trusty PM, Bhat SS, Sadri V, Salim MT, Funnell E, Kamioka N, et al. The role of flow stasis in transcatheter aortic valve leaflet thrombosis. J Thorac Cardiovasc Surg. November 26, 2020 [Epub ahead of print].

23. Midha A, Raghav V, Sharma R, Condado JF, Okafor IU, Rami T, et al. The fluid mechanics of transcatheter heart valve leaflet thrombosis in the neosinus. Circulation. 2017;136:1598-609.

24. Yamashita K, Yagi H, Hayakawa M, Abe T, Hayata Y, Yamaguchi N, et al. Rapid restoration of thrombus formation and high-molecular-weight von willebrand factor multimers in patients with severe aortic stenosis after valve replacement J Atheroscler Thromb. 2016;23:1150-8.

25. Rheude T, Pellegrini C, Stortecky S, Marwan M, Xhepa E, Ammon F, et al. Metaanalysis of bioprosthetic valve thrombosis after transcatheter aortic valve implantation. Am J Cardiol. 2021;138:92-9.

26. Del Trigo M, Muñoz-García AJ, Latib A, Auffret V, Wijeysurendra HC, NombelaFranco L, et al. Impact of anticoagulation therapy on valve haemodynamic deterioration following transcatheter aortic valve replacement. Heart. 2018;104:814.

27. Cartlidge TRG, Doris MK, Sellers SL, Pawade TA, White AC, Pessotto R, et al. Detection and prediction of bioprosthetic aortic valve degeneration. J Am Coll Cardiol. 2019;73:1107-19.

28. Sellers SL, Turner CT, Sathananthan J, Cartlidge TRG, Sin F, Bouchareb R, et al Transcatheter aortic heart valves: histological analysis providing insight to leaflet thickening and structural valve degeneration. JACC Cardiovasc Imaging. 2019 $12: 135-45$.

29. Sondergaard L, De Backer O, Kofoed KF, Jilaihawi H, Fuchs A, Chakravarty T, et al. Natural history of subclinical leaflet thrombosis affecting motion in bioprosthetic aortic valves. Eur Heart J. 2017;38:2201-7.

30. Otto CM, Nishimura RA, Bonow RO, Carabello BA, Erwin JP III, Gentile F, et al 2020 ACC/AHA guideline for the management of patients with valvular heart disease: executive summary: a report of the American College of Cardiology/ American Heart Association Joint Committee on clinical practice guidelines Circulation. 2021;143:e35-71.

31. Ruile P, Jander N, Blanke P, Schoechlin S, Reinohl J, Gick M, et al. Course of early subclinical leaflet thrombosis after transcatheter aortic valve implantation with or without oral anticoagulation. Clin Res Cardiol. 2017;106:85-95.

32. Chakravarty T, Patel A, Kapadia S, Raschpichler M, Smalling RW, Szeto WY, et al. Anticoagulation after surgical or transcatheter bioprosthetic aortic valve replacement. J Am Coll Cardiol. 2019;74:1190-200.

33. De Backer O, Dangas GD, Jilaihawi H, Leipsic JA, Terkelsen CJ, Makkar R, et al Reduced leaflet motion after transcatheter aortic-valve replacement. $N$ Engl J Med. 2019;382:130-9.

34. Rogers T, Shults C, Torguson R, Shea C, Parikh P, Bilfinger T, et al. Randomized trial of aspirin versus warfarin after transcatheter aortic valve replacement in lowrisk patients. Circ Cardiovasc Interv. 2021;14:e009983.

35. Dangas GD, Tijssen JGP, Wöhrle J, Sondergaard L, Gilard M, Möllmann H, et al A controlled trial of rivaroxaban after transcatheter aortic-valve replacement. $N$ Engl J Med. 2019;382:120-9.

36. Fioretta ES, Motta SE, Lintas V, Loerakker S, Parker KK, Baaijens FPT, et al. Next-generation tissue-engineered heart valves with repair, remodelling and regeneration capacity. Nat Rev Cardiol. 2021;18:92-116.

Key Words: TAVR, SAVR, leaflet thrombosis, HALT, RLM, durability, structural valve degeneration 